IMAGE

UNAVAILABLE

FOR COPYRIGHT

REASONS

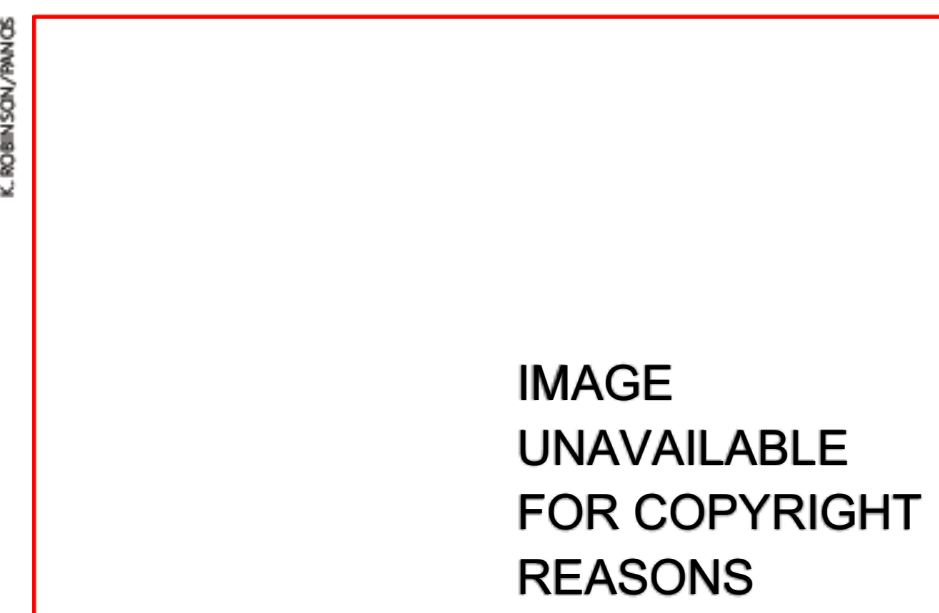

Clouded outlooks researchers' predictions of reducedrainfall in India this year clash with government data.

\title{
Rival monsoon forecasts banned
}

\section{NEW DELHI}

Researchers at a dimate institute in India have voiced concern at what they see as attempts by the government to curb their scientific freedom after they were forced to remove monsoon forecasts from their website. The government says the move is necessary to stop the public being confused by conflicting forecasts. But the scientists are worried that it could prevent researchers in a range of disciplines from communicating their results.

India receives $90 \%$ of its rain during the monsoon months of June to September. The economy relies heavily on farming, and so an accurate forecast is critical for sowing seeds at the right time and choosing appropriate crops.

But the monsoon season is notoriously difficult to predict. The country's official forecast comes from the India Meteorological Department (IMD), which is run by the government's Department of Science and Technology (DST). To predict rainfall, it uses a model based on statistics of past monsoons.

In 2002, scientists at the Center for Mathematical Modelling and Computer Simulation (C-MMACS) in Bangalore began forecasting the monsoon with a more sophisticated globalclimate model that uses equations to describe Earth's atmosphere. Since 2003, the researchers have been posting the results on their website, and the Indian media have been reporting them.

Last month, the DST issued a directive prohibiting the publication of any results that differ from its official forecast unless they have been peer-reviewed and cleared by the head of the researchers' agency. The DST will in future collect and disseminate monsoon data produced by research institutes to avoid confusion, DST secretary Valangiman Ramamurthi told Nature. "Monsoon forecasting is sensitive for the Indian economy," he says. "It's not a free-for-all.

Prashant Goswami, who heads the monsoon research group at the C-MMACS, says he and his colleagues are upset at the directive. "Posting unpublished results on the web is the accepted norm in science everywhere," he points out. "What upsets us is that we have a monsoon model that seems to work, but we can't make the results public." $\mathrm{He}$ is also concerned over the implications for other research fields. "I hope this will be debated by the scientific community, he says.

The DST has not specified the other areas of research to which the directive will apply, although Ramamurthi told Nature that guidelines will be issued soon. He says the policy is in the public interest and denies the government is restricting researchers' freedom. "All we said was that before putting anything on the web, get it cleared by the head of your agency, he asserts.

C-MMACS director Gangan Prathap speculates that the order may have been triggered by the fact that his institute's forecast of rainfall levels $34 \%$ below average in June and $12 \%$ below average in July is dramatically different from the "normal or above normal" rains predicted by the government.

Madhavan Nair Rajeevan, director of the IMD's National Climate Centre in Pune, admits that the department's monsoon predictions have not improved in the 70 years since they began. "The IMD's model has limitations at district level and its forecasts have been off the mark quite often," Rajeevan told Nature. "But it is still the best available for forecasting at an all-India level. ${ }^{\text {}} \mathrm{He}$ says the clampdown on unvetted forecasts is justified, but adds that his team is looking at switching to a climate model.

In its 27 June bulletin, the IMD admitted that June's rainfall was $35 \%$ below average - as forecast by the C-MMACS. Heavy rains in Gujarat over the following three days reduced the deficit to $20 \%$, and the IMD insists that this will be made up in the next few months to make 2005 a normal year, as it predicted.

K.S.Jayaraman 